\title{
Implementasi Algoritma Apriori untuk Rekomendasi Kombinasi Produk Penjualan
}

\author{
Andre Setiawan ${ }^{1}$, Farica Perdana Putri ${ }^{2}$ \\ ${ }^{1,2}$ Program Studi Informatika, Universitas Multimedia Nusantara, Tangerang, Indonesia \\ andre.setiawan@student.umn.ac.id \\ farica@umn.ac.id
}

Diterima 8 Juni 2020

Disetujui 17 Juni 2020

\begin{abstract}
Analyzing and systematically extracting essential information from recording transactions is important for a business, including online stores. Sometimes, some online stores offer a product package that is not suitable for the customer. It happens because they did not process the data transaction to observe the association between products on a package. A webbased recommendation system was build using the CodeIgniter framework with PHP programming language. The system developed using Market Basket analysis that can determine the combination of products. Apriori algorithm used as a technique to analyze the relationship between products based on the data transaction. The lift ratio value generated from the rule is 1.18, which means that the rule has the power of relationships between items. We evaluate the system using USE questionnaire with usefulness results is $90.83 \%$, ease of use $89.09 \%$, ease of learning $95 \%$, and satisfaction $90.94 \%$, which strongly agree in every aspect.
\end{abstract}

Index Terms-Apriori, CodeIgniter, Lift Ratio, Market Basket Analysis, Recommendation

\section{PENDAHULUAN}

PT Grup Gaga Indonesia atau biasa disebut sebagai Party Gaga adalah sebuah toko daring di Indonesia yang menawarkan berbagai pilihan kebutuhan pesta yang membuat jauh lebih mudah, terjangkau dan menyenangkan untuk mendekorasi, serta meningkatkan pengalaman acara agar lebih mengesankan [1].

Dalam proses penjualan jasa ataupun barang, seringkali toko daring menggunakan kombinasi produk yang kurang tepat sasaran dan diminati oleh para pembeli [2]. Hal ini tentunya dapat menurunkan tingkat penjualan karena barang-barang tersebut yang jarang dibeli pembeli secara bersamaan. Lalu, pemahaman dan definisi yang tepat akan suatu masalah merupakan hal yang penting dalam menciptakan suatu solusi software yang tepat [3]. Maka dari itu, melakukan kombinasi produk penjualan dari data transaksi yang ada, bisa menguntungkan toko daring karena barang yang dikombinasikan berdasarkan barang yang paling sering dibeli oleh pembeli. Rekomendasi kombinasi produk (itemset) tersebut dapat menggunakan metode Market Basket Analysis karena mendukung sistem rekomendasi melalui penemuan pola antar item dalam transaksi-transaksi yang terjadi [4].

Market Basket Analysis ini dianggap mampu memberikan jalan keluar dalam merekomendasikan kombinasi kategori produk yang terkait dengan penggunaan algoritma Apriori melalui metode Association Rules [5]. Algoritma Apriori adalah suatu metode di mana akan mencari pola hubungan antar satu atau 3 lebih item dalam sebuah dataset [6]. Kelebihan algoritma Apriori adalah jumlah kandidat yang harus dihitung support-nya dapat dikurangi dengan cara pemangkasan sehingga memiliki performa yang baik [7].

Pemahaman dan definisi yang tepat akan suatu masalah merupakan hal yang penting dalam menciptakan suatu solusi software yang tepat. Untuk itu, diperlukan proses-proses untuk menemukan, memahami, memformulasi, menganalisis, dan menemui persetujuan terkait masalah apa yang harus diselesaikan, kenapa masalah tersebut harus diselesaikan, dan siapa yang harus terlibat dalam penyelesaian masalah tersebut. Secara umum, proses analisis kebutuhan meliputi hal-hal yang telah disebutkan di atas

Penelitian terkait yang pernah dilakukan, dihasilkan sejumlah kombinasi item set yang cocok untuk pemasaran ini dan kekuatan hubungan antar item dapat dipercaya dan dijadikan acuan karena ketepatan kombinasi item set yang dihasilkan valid karena semua nilai lift ratio-nya > 1 [8]. Lift ratio digunakan untuk mengukur seberapa penting aturan atau yang telah terbentuk agar dapat dipercaya sepenuhnya [9].

\section{LANDASAN TEORI}

\section{A. Market Basket Analysis}

Market Basket Analysis digunakan untuk mengetahui produk yang dibeli secara bersamaan oleh pelanggan agar dapat meningkatkan taktik pemasaran dan penjualan di tingkat toko [10]. Istilah Market 
Basket Analysis masuk dalam kategori Association Rules. Association Rule adalah sebuah ekspresi implikasi dari bentuk $A \rightarrow B$, di mana $A$ dan $B$ adalah itemset yang saling terpisah (disjoint), dengan kata lain $A \cap B=\emptyset$. Dalam menentukan Association Rule, terdapat suatu ukuran ketertarikan yang didapatkan dari hasil pengolahan data dengan perhitungan tertentu, yaitu sebagai berikut [11].

1. Support: bagian transaksi yang mengandung kedua $A$ dan $B$.

$$
\begin{aligned}
& \text { Support }(A)= \\
& \text { Jumlah transaksi mengandung } A
\end{aligned}
$$
Total transaksi

Atau jika terdapat dua buah item dalam $A$, nilai support diperoleh dari rumus sebagai berikut.

$$
\begin{aligned}
& \text { Support }(A)= \\
& \text { Jumlah transaksi mengandung } A
\end{aligned}
$$

Total transaksi

2. Confidence: seberapa sering item dalam $B$ muncul di transaksi yang mengandung $A$.

$$
\begin{aligned}
& \text { Confidence } P(A \backslash B)= \\
& \frac{\text { Jumlah transaksi mengandung } A \text { dan } B}{\text { Total transaksi mengandung } A}
\end{aligned}
$$

\section{B. Apriori}

Apriori adalah salah satu pendekatan yang sering digunakan pada Frequent Itemset Mining. Prinsip algoritma Apriori adalah jika sebuah itemset infrequent, maka itemset yang infrequent tidak perlu lagi dieksplor superset sehingga jumlah kandidat yang harus diperiksa menjadi berkurang, berikut adalah ilustrasinya [11].

Langkah-langkah Apriori adalah sebagai berikut [12]:

1. Tentukan minimum support (nilai minimum dari kombinasi item).

2. Pembentukan kandidat itemset $\left(C_{k}\right)$ dibangun dengan menggabungkan $L_{k-1}$, dengan dirinya sendiri.

3. Pemangkasan kandidat itemset dilakukan setiap $C_{k}$-itemset yang tidak sering muncul (not frequent) tidak dapat menjadi subset dari frequent $\mathrm{k}$-itemset.

4. Menentukan support dari kombinasi k-itemset sebelumnya. Itemset yang memenuhi minimum support akan dipilih sebagai pola frequent tinggi $\left(L_{k}\right)$ dari kandidat.
5. Tetapkan nilai k-itemset dari support yang telah memenuhi minimum support dari k-itemset.

6. Jika sudah tidak ada lagi k-itemset yang memenuhi minimum support maka proses dihentikan.

\section{Lift Ratio}

Lift ratio merupakan nilai yang menunjukan kevalidan proses transaksi dan memberikan informasi apakah benar item A dibeli bersamaan item B, dengan rumus sebagai berikut [9].

$$
\text { Nilai lift }=\frac{\text { Support }(A \cap B)}{\text { Support }(A) x \text { Support }(B)}
$$

Sebuah transaksi dikatakan valid, jika mempunyai nilai lift ratio lebih dari 1, yang berarti bahwa dalam transaksi tersebut item A dan item B benar-benar dibeli secara bersamaan [9].

\section{White Box}

White Box digunakan untuk menguji suatu aplikasi di mana struktur internal telah diketahui oleh penguji [13]. Ada beberapa cara dalam melakukan uji coba white box, salah satunya adalah Unit Testing. Unit Testing merupakan pengujian dilakukan pada setiap modul atau blok kode selama pengembangan. Pengujian ini biasa dilakukan oleh developer yang menulis kode [13]. Teknik pada Unit Testing ada beberapa, salah satunya adalah Path Coverage. Path Coverage merupakan uji coba untuk memastikan bahwa setiap alur program dapat dilalui setindaknya satu kali [14].

\section{E. USE Questionnaire}

USE questionnaire adalah salah satu paket kuesioner yang dapat digunakan untuk mengevaluasi website yang dibangun dari segi usability. Secara umum, usability mengacu pada sejauh mana kepuasan user dan sejauh mana user dapat belajar dan menggunakan suatu produk untuk mencapai tujuannya [15]. USE memiliki beberapa aspek yaitu, usefulness, ease of use, ease of learning, satisfaction. Meskipun ditemukan beberapa dimensi lain, tetapi aspek ini merupakan yang paling mudah diamati dan dibandingkan hasilnya [15].

Lalu paket kuesioner yang akan digunakan selengkapnya dapat dilihat pada tabel di bawah ini [16].

Tabel 1. Kriteria pengukuran USE questionnaire

\begin{tabular}{|c|l|}
\hline No & \multicolumn{1}{|c|}{ Kriteria } \\
\hline & Usefulness \\
\hline $\mathrm{U} 1$ & It helps me be more effective. \\
\hline $\mathrm{U} 2$ & It helps me be more productive. \\
\hline
\end{tabular}


ISSN 2085-4552

\begin{tabular}{|c|c|c|c|}
\hline No & \multirow[b]{2}{*}{ Usefulness } & \multirow{4}{*}{\multicolumn{2}{|c|}{$\begin{array}{l}\text { pertanyaan, sangat setuju (SS), setuju (S), netral (N) } \\
\text { tidak setuju (TS) dan sangat tidak setuju (STS) [18]. } \\
\text { Tabel 2. Skor skala Likert }\end{array}$}} \\
\hline & & & \\
\hline $\mathrm{U} 3$ & It is useful. & & \\
\hline $\mathrm{U} 4$ & It gives me more control over the activities in my life. & & \\
\hline U5 & It make the things I want to accomplish easier to get & $\begin{array}{c}\text { Angka } \\
(\%)\end{array}$ & Jawaban \\
\hline U6 & $\begin{array}{l}\text { done. } \\
\text { It saves me time when Luse it }\end{array}$ & 1 & Sangat Tidak Setuju \\
\hline 06 & It saves me time when I use it. & 2 & Tidak Setuju \\
\hline U18 & It does evervthing I would expect it to do & 3 & Netral \\
\hline & Ease of Use & 4 & Setuju \\
\hline EU1 & It is easy to use. & 5 & Sangat Setuju \\
\hline
\end{tabular}

\begin{tabular}{|c|l|}
\hline EU1 & It is easy to use. \\
\hline EU2 & It is simple to use. \\
\hline EU3 & It is user friendly. \\
\hline
\end{tabular}

Persetasi skor pada pertanyaan kuesioner dapat dihitung dengan menggunakan Rumus 5 [17].

$$
\frac{(S S * 5)+(S * 4)+(N * 3)+(T S * 2)+(S T * 1)}{S * \text { Jumlah responden })} * 100 \%
$$

\begin{tabular}{|l|l|}
\hline EU5 & It is flexible. \\
\hline EU6 & Using it is effortless. \\
\hline EU7 & I can use it without written instructions. \\
\hline EU8 & I don't notice any inconsistencies as I use it. \\
\hline EU9 & Both occasional and regular users would like it. \\
\hline EU10 & I can recover from mistakes quickly and easily. \\
\hline EU11 & I can use it successfully every time. \\
\hline & Ease of Learning \\
\hline EL1 & I learned to use it quickly. \\
\hline EL1 & I easily remember how to use it. \\
\hline EL1 & It is easy to learn to use it. \\
\hline EL1 & It is quickly became skillful with it. \\
\hline & Satisfaction \\
\hline S1 & I am satisfied with it. \\
\hline S2 & I would recommend it to a friend. \\
\hline S3 & It is fun to use. \\
\hline S4 & It works the way I want it to work. \\
\hline S6 & It is wonderful. \\
\hline Ifeel I need to have it. \\
\hline It is pleasant to use. \\
\hline S6
\end{tabular}

\section{F. Skala Likert}

Evaluasi website dalam penelitian ini menggunakan USE quesionnaire. Kuesioner ini menggunakan skala Likert sebagai pengukuran aspeknya. Skala Likert digunakan untuk mengukur sikap, pendapat dan persepsi seseorang atau sekelompok orang tentang kejadian atau fenomena sosial [17]. Skala Likert menggunakan beberapa butir pertanyaan untuk mengukur perilaku individu dengan merespon lima titik pilihan pada setiap butir

Tabel 3. Kategori kelayakan

\begin{tabular}{|c|c|}
\hline $\begin{array}{c}\text { Angka } \\
(\%)\end{array}$ & Jawaban \\
\hline$<21$ & Sangat Tidak Layak \\
\hline $21-40$ & Tida Layak \\
\hline $41-60$ & Cukup \\
\hline $61-80$ & Layak \\
\hline $81-100$ & Sangat Layak \\
\hline
\end{tabular}

Persentasi skor yang diperoleh kemudian akan disesuaikan nilai yang didapat berdasarkan Tabel 3 [16].

\section{Metodologi Penelitian}

\section{A. Telaah Literatur}

Bentuk kegiatan dalam pengumpulan berbagai informasi pada tahap ini mulai dari jurnal-jurnal, buku ataupun referensi penelitian-penelitian yang berkaitan dengan penelitian yang akan dilakukan. Tahapan ini adalah proses awal penelitian yang akan dilakukan.

\section{B. Pengumpulan Data}

Data yang dikumpulkan dalam penelitian ini berasal dari data transaksi yang tercatat pada PT Grup Gaga Indonesia. Data yang diperoleh adalah transaksi dalam jangka waktu 2 tahun dimulai dari 1 Januari 2016 sampai 31 Desember 2018 dengan total jumlah data adalah 529 transaksi.

\section{Perancangan}

Gambar 1 merupakan sitemap dari website yang akan digunakan oleh pemilik toko daring. 


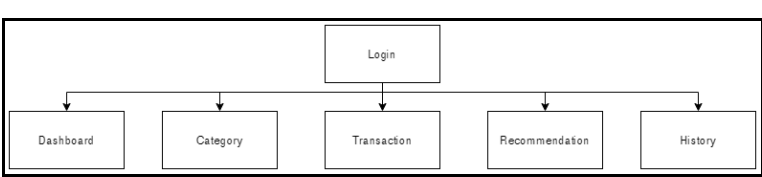

Gambar 1. Sitemap

Perancangan website dilakukan dengan membuat struktur halaman website. Halaman login adalah halaman pertama saat admin membuka website. Setelah login, admin dapat bernavigasi ke halaman dashboard, category, transaction, recommendation, dan history.

\section{Uji Coba dan Evaluasi}

Pada tahap ini, dilakukan pembentukan association rules dengan algoritma Apriori. Adapun langkah-langkah yang dilakukan sesuai dengan yang dijelaskan pada Sub-bab II pada Landasan Teori. Perhitungan lift ratio dilakukan untuk mengetahui tingkat korelasi antar produk.

\section{IMPLEMENTASI DAN UJI COBA}

\section{A. Implementasi}

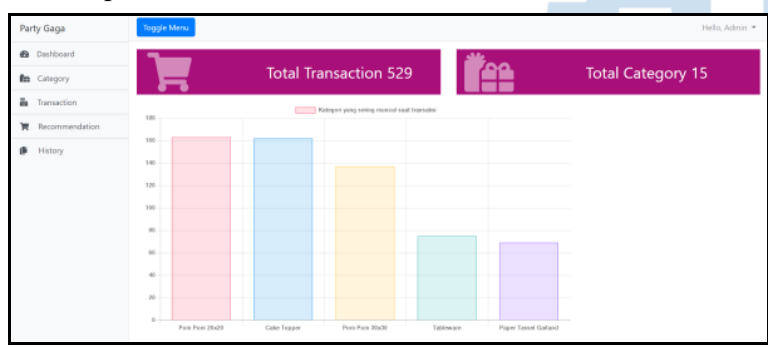

Gambar 2. Halaman dashboard

Gambar 2 merupakan halaman dashboard. Terdapat sidebar pada bagian sebelah kiri dan menampilkan total transaksi, total kategori dan grafik pada bagian tengah.

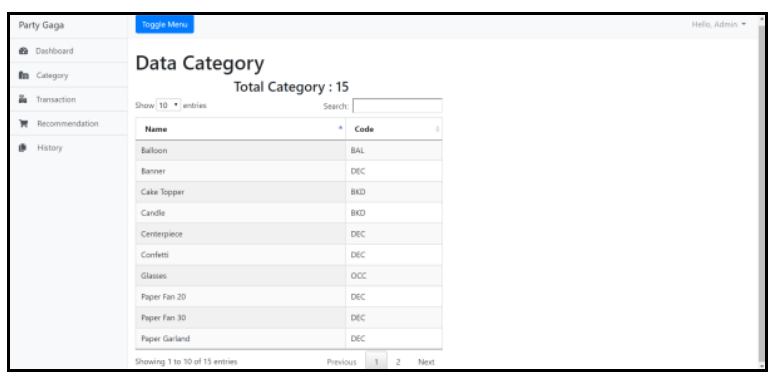

Gambar 3. Halaman category

Gambar 3 merupakan halaman category. Halaman ini menampilkan tabel data kategori.

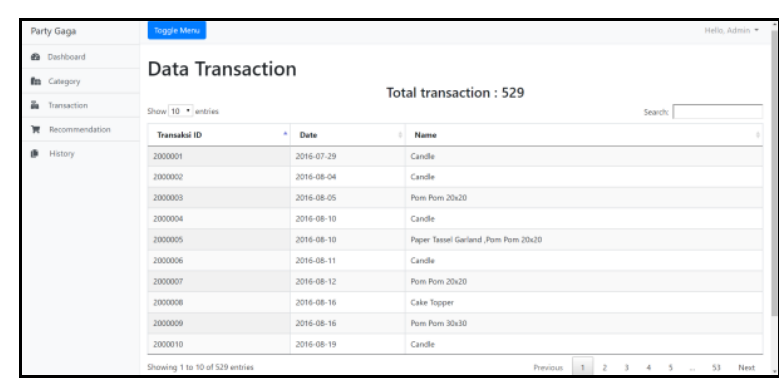

Gambar 4. Halaman transaction

Gambar 4 merupakan halaman transaction. Halaman ini menampilkan tabel data transaksi.

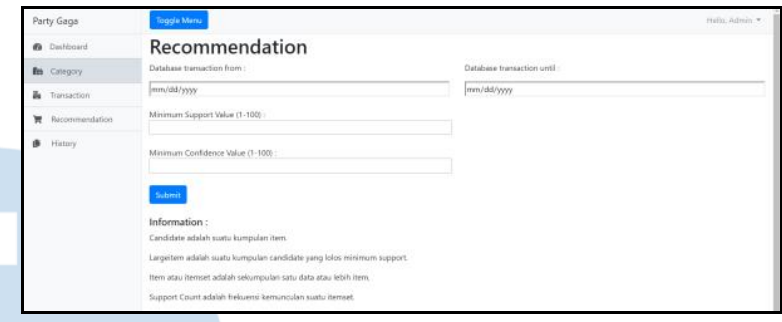

Gambar 5. Halaman recommendation

Gambar 5 merupakan halaman recommendation. Halaman ini menampilkan field input tanggal transaksi dari, tanggal transaksi sampai, nilai minimum support, nilai minimum confidence, serta terdapat keterangan yang menjelaskan istilah-istilah.

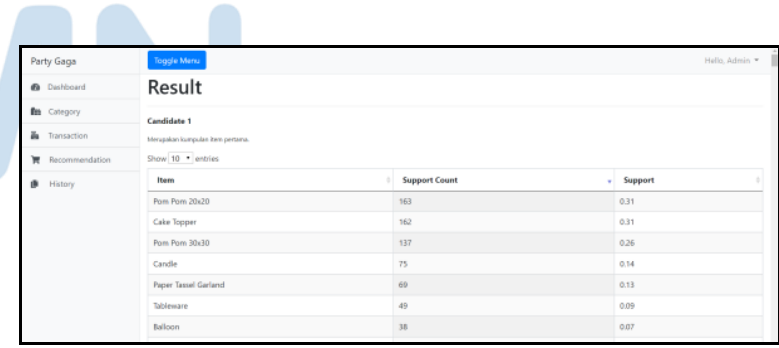

Gambar 6. Halaman hasil recommendation

Gambar 6 merupakan halaman hasil recommendation. Halaman ini menampilkan hasil dari proses yang dilakukan. 


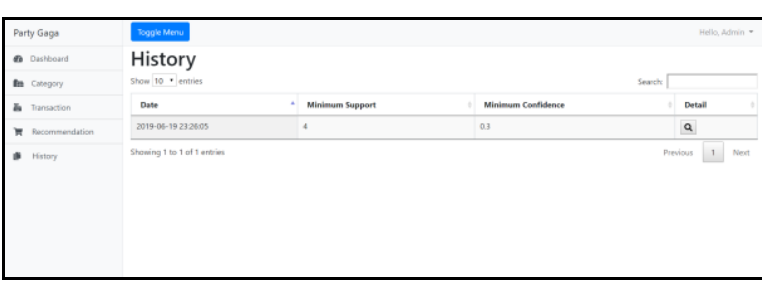

Gambar 7. Halaman history

Gambar 7 merupakan halaman history. Halaman ini menampilkan tabel dari setiap proses yang dilakukan. Ikon detail akan menavigasi halaman ke history detail.

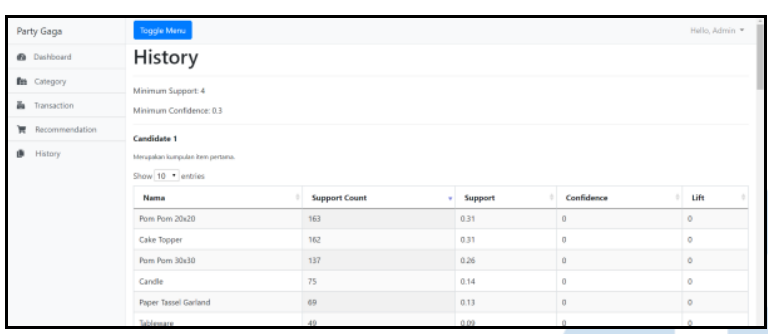

Gambar 8. Halaman history detail

Gambar 8 merupakan halaman history detail. Halaman ini menampilkan data history dari setiap history yang dipilih.

\section{B. Hasil Rekomendasi}

Dataset menggunakan data sebesar 529 data transaksi dengan minimum support sebesar 4 dan minimum confidence 0.3. Lalu item yang suppport count tidak memenuhi minimum support akan dihapus.

Tabel 5 menampilkan rekap nilai hasil perhitungan terhadap algoritma Apriori. Pengambilan rekomendasi kombinasi produk merupakan perhitungan dari nilai support, confidence dan lift ratio. Kolom support count menunjukkan jumlah kemunculan suatu aturan (association rules). Kolom support menunjukkan nilai dari aturan yang dihasilkan. Kolom confidence menunjukkan suatu nilai kepastian atau kehandalan dari aturan yang dibuat. Kemudian, nilai lift ratio menunjukkan nilai evaluasi kuat tidaknya sebuah aturan. Kombinasi atau aturan yang muncul telah memenuhi nilai minimum support 4 , minimum confidence 0.3 , dan memenuhi nilai lift ratio $>1$.

Tabel 5. Hasil perhitungan

\begin{tabular}{|l|l|l|l|c|c|c|c|}
\hline Jika & $\begin{array}{c}\text { Su } \\
\text { pp } \\
\text { ort } \\
\text { A }\end{array}$ & $\begin{array}{c}\text { Ma } \\
\text { ka }\end{array}$ & $\begin{array}{c}\text { Supp } \\
\text { ort C }\end{array}$ & $\begin{array}{c}\text { Supp } \\
\text { ort } \\
\text { Coun } \\
\mathbf{t}\end{array}$ & $\begin{array}{c}\text { Supp } \\
\text { ort } \\
(\mathbf{A , C} \\
\text { ), }\end{array}$ & Conf & $\begin{array}{c}\text { Li } \\
\mathbf{f t}\end{array}$ \\
\hline $\begin{array}{l}\text { Pom } \\
\text { Pom } \\
\text { 20x20 }\end{array}$ & $\begin{array}{l}0,3 \\
1\end{array}$ & $\begin{array}{l}\text { Cake } \\
\text { Topp } \\
\text { er }\end{array}$ & 0,31 & 42 & 0,08 & 0,26 & 0, \\
\hline
\end{tabular}

\begin{tabular}{|c|c|c|c|c|c|c|c|}
\hline Jika & $\begin{array}{c}\text { Su } \\
\text { pp } \\
\text { ort } \\
\text { A }\end{array}$ & $\begin{array}{c}\text { Ma } \\
\text { ka }\end{array}$ & $\begin{array}{l}\text { Supp } \\
\text { ort C }\end{array}$ & $\begin{array}{c}\text { Supp } \\
\text { ort } \\
\text { Coun } \\
t\end{array}$ & $\begin{array}{c}\text { Supp } \\
\text { ort } \\
(\mathrm{A}, \mathrm{C} \\
\text { ) }\end{array}$ & Conf & $\begin{array}{l}\mathbf{L i} \\
\mathbf{f t}\end{array}$ \\
\hline $\begin{array}{l}\text { Pom } \\
\text { Pom } \\
20 \times 20\end{array}$ & $\begin{array}{l}0,3 \\
1\end{array}$ & $\begin{array}{l}\text { Pom } \\
\text { Pom } \\
30 \times 3 \\
0\end{array}$ & 0,26 & 100 & 0,19 & 0,61 & $\begin{array}{l}2, \\
37\end{array}$ \\
\hline $\begin{array}{l}\text { Cake } \\
\text { Topper }\end{array}$ & $\begin{array}{l}0,3 \\
1\end{array}$ & $\begin{array}{l}\text { Pom } \\
\text { Pom } \\
30 \times 3 \\
0\end{array}$ & 0,26 & 40 & 0,08 & 0,29 & $\begin{array}{l}0, \\
95\end{array}$ \\
\hline $\begin{array}{l}\text { Pom } \\
\text { Pom } \\
20 \times 20 \\
\text { Pom } \\
\text { Pom } \\
30 \times 30 \\
\end{array}$ & $\begin{array}{l}0,1 \\
9\end{array}$ & $\begin{array}{c}\text { Cake } \\
\text { Topp } \\
\text { er }\end{array}$ & 0,31 & 36 & 0,07 & 0,36 & $\begin{array}{l}1, \\
18\end{array}$ \\
\hline
\end{tabular}

\section{Uji Coba White Box}

Uji coba dilakukan pada halaman Recommendation dengan Unit Testing. Teknik Unit Testing yang akan digunakan adalah Path Testing. Setiap uji coba yang dilakukan berhasil dijalankan sehingga kode pada halaman Recommendation memiliki 100 persen path coverage.

\section{Evaluasi Sistem}

Dari keempat aspek yang telah diperoleh hasil nilainya, aspek ease of use merupakan skor paling rendah dengan $89.09 \%$ yang dikarenakan setengah dari responden pada pertanyaan nomor enam memilih skor netral. Kemudian aspek usefulness, ease of learning, satisfaction memperoleh persentase skor lebih dari $90 \%$ yang bisa disimpulkan bahwa hampir semua responden menyatakan sangat layak berdasarkan Tabel 3 atau sangat setuju pada setiap aspek.

Tabel 6. Hasil evaluasi system

\begin{tabular}{|l|c|}
\hline \multicolumn{1}{|c|}{ Aspek } & Perhitungan Skor \\
\hline Usefulness (Kegunaan) & $90,83 \%$ \\
\hline Ease of Use (Kemudahan Penggunaan) & $89,09 \%$ \\
\hline Ease of Learning (Kemudahan Belajar) & $95 \%$ \\
\hline Satisfaftion (Kepuasan) & $90,94 \%$ \\
\hline
\end{tabular}

\section{SIMPULAN}

Sistem rekomendasi kombinasi produk yang sering dibeli secara bersamaan yaitu Pom Pom 20x20, Pom Pom 30x30 dan Cake Topper. Website ini dilakukan pengujian menggunakan white box untuk memastikan alur program dapat dilalui setidaknya satu kali dan dievaluasi menggunakan USE Questionnaire dengan hasil pada usefulnes $90.83 \%$, ease of use $89.09 \%$, ease of learning 95\% dan satisfaction $90.94 \%$ yang menyatakan sangat layak atau setuju pada setiap aspek. Nilai lift ratio yang dihasilkan dari aturan menunjukkan 1.18 dari Pom 
Pom 20x20, Pom Pom 30x30 dan Cake Topper yang artinya bahwa aturan tersebut memiliki kekuatan hubungan antar item sehingga dapat dipercaya untuk dijadikan kombinasi item.

\section{DAFTAR PUSTAKA}

[1] PT. Grup Gaga Indonesia, 2018. Katalog online.

[2] A. Kusnadi, J. Pratama, "Implementasi Algoritma Genetika dan Neural Network Pada Aplikasi Peramalam Produksi Mie (Studi Kasus: Omega Mie Jaya), ULTIMATICS, Vol. IX, No $1,2017$.

[3] A. Rusli, "Ekstrasi Kebutuhan Aplikasi Berdasarkan Feedback Pengguna Menggunakan Naïve Bayes dan Gamifikasi”, ULTIMATICS, Vol X, No 1, 2018.

[4] A. Masnur, "Analisa Data Mining Menggunakan Market Basket Analysis untuk Mengetahui Pola Beli Konsumen" Vol. 1, No. 2, 2015

[5] M. Riadi. kajianpustaka.com. 2017. [Online] Tersedia dalam: https://www.kajianpustaka.com/2017/09/data-mining.html [Diakses 21 Juni 2018].

[6] H.D. Anggraeni, "Aplikasi Data Mining Analisis Data Transaksi Penjualan Obat Menggunakan Algoritma Apriori (Studi Kasus di Apotek Setya Sehat Semarang)" Volume 4, 2013

[7] O. S. A. Destiyati, E. Aribowo, "Analisis Perbandingan Algoritma Apriori dan Algoritma Hash Based pada Market Basket Analysis di Apotek UAD", Jurnal Sarjana Teknik Informatika, Vol 3 No 1, 2015.

[8] D. Fitriati, "Implementasi Data Mining untuk Menentukan Kombinasi Media Promosi Barang Berdasarkan Perilaku Pembelian Pelanggan Menggunakan Algoritma Apriori", Annual Research Seminar, 2016.

[9] E. Widiati, "Implementasi Association Rule Terhadap Penyusunan Layout Makanan dan Penentuan Paket Makanan
Hemat di RM Roso Echo Dengan Algoritma Apriori” Jurnal Ilmiah Komputer dan Informatika, Vol 3, No 2, 2013.

[10] M. Kaur, S. Kang, "Market Basket Analysis: Identify the changing trends of market data using association rule mining", International Coference on Computational Modeling and Security, 2016.

[11] Christie, D. A., Baskoro, D.A., Ambarwati, L. \& Wicaksana I.W.S. (2013). Belajar Data Mining dengan Rapid Miner, Jakarta.

[12] Larose, D.T. (2014). Discovering Knowledge in Data: An Introduction to Data Mining.

[13] P. Kurniawati. medium.com. 2018. [Online] Tersedia dalam : https://medium.com/skyshidigital/pengujian-sistem52940ee98c77_[Diakses 3 Januari 2019].

[14] Softwaretestinghelp. 2019. softwaretestinghelp.com [Online] Tersedia dalam: https://www.softwaretestinghelp.com/whitebox-testing-techniques-with-example/.

[15] K. Aelani, Falahah, "Pengukuran Usability Sistem Menggunakan USE Questionnaire (Studi Kasus Perwalian Online STMIK "AMIKBANDUNG")", Seminar Nasional Aplikasi Teknologi Informasi, 2012.

[16] W. Kusuma, dan G. I. Marthasari, "Analisis Usability dalam User Experience pada Sistem KRS Online UMM menggunakan USE Questionnaire", ResearchGate, 2016.

[17] Sugiyono, "Metodologi Penelitian Kuantitatif, Kualitatif dan R\&D”, Bandung: Alfabeta, 2012

[18] Budiaji, W. (2013). Skala Pengukuran dan Jumlah Respon Skala Likert, Jurnal Ilmu Pertanian dan Perikanan, Volume 2.

[19] Sharma, M., Choudhary, J., Sharma, G, "Evaluating The Performance of Apriori and Predictive Apriori Algorithm To Find New Association Rules Based On The Statiscal Measures of Datasets.", International Jounrak of engineering Research \& Technology, Vol 1 Issue 6, 2012. 